Transgender identities, pressures and social policy: A study carried out in Spain.

\title{
Noelia Fernández-Rouco
}

(Department of Education)University of Cantabria, Spain. Ph.D. Associate Professor.

\section{Rodrigo J Carcedo}

(Department of Developmental and Educational Psychology) University of Salamanca, Spain.

$\mathrm{Ph}: \mathrm{D}$. Associate Professor.

Email: rcarcedo@usal.es

\section{Tray Yeadon-Lee}

(Department of Behavioral \& Social Sciences) University of Huddersfield, United Kingdom.

Ph.D. Senior Lecturer in Sociology

Email: T.Yeadon-Lee@hud.ac.uk

\section{Corresponding author:}

Noelia Fernández-Rouco, Department of

Education, University of Cantabria, Avda. Los

Castros, s/n, 39005, Santander, Spain.

Phone: (0034) 942.20.11.79

Fax: (0034) 942.20.11.73

Email: fernandezrn@unican.es 
Transgender identities, pressures and social policy: A study carried out in Spain.

\begin{abstract}
This paper draws on a qualitative research project concerning the relationship between trans people's mental health and well-being, pressures, social policy and heteronormative gender norms in Spain. Drawing on interviews carried out with trans people from all regions and generations, we utilize an ecological framework to illustrate how a socially entrenched heteronormativity, pressures trans people to comply with gender norms that impact negatively upon their mental health and well being. The paper argues that the legal changes in Spain are not enough in themselves to bring about social change, but rather, Spanish social policy makers also need to challenge gender categorization, and work towards transforming public discourses on gender issues if trans people are to gain full social recognition and equal social rights.
\end{abstract}

\title{
Keywords
}

Transgender; Sexuality; Spanish; Stigma; Heteronormativity; Pressures; Relationships 


\section{Trans people in Spain: the social and legal context}

Gender identity has recently become a political issue in Spain, where the situation of trans people has significantly changed in the last 40 years. During the Franco era gender identity and sexual orientation were conflated and gender correction surgery was considered a crime. Trans people were considered to be homosexuals and were prosecuted under the 1954 national law for 'Slackers and Delinquents' (in Spanish, Ley de Vagos y Maleantes), and the 1970 national law for 'Social Danger and Rehabilitation' (in Spanish, Ley sobre Peligrosidad y Rehabilitación Social). These laws were not repealed until the 1980s, where living as a trans person and gender correction surgeries were no longer included in the classification of crimes. In 1995, the New Spanish Penal Code incorporated that, one of the aggravating factors of any crime is having committed it for sexual identity and/or gender reasons. The situation for trans people has, however, continued to be regulated. For example, until 2007, changing ones name and sex on the Spanish identification card, required strict engagement with judicial processes. Later, the introduction of the 3/2007 law, the first Spanish law to formally recognize the right to change the name and sex on Spanish identification cards, brought two significant benefits. First, it removed the previous judicial process and, second, it brought forth the formal recognition of a need to address social inequalities and support trans people's rights. One of the positive advances of this law was that trans people were not required to undergo genital surgery in order to legally change their gender status. However, with the introduction of this law there were two strict requirements. First, trans people were required to undergo a strict medical and psychological evaluation, and second they were required to gain a medical diagnosis of "gender dysphoria", linked to trans trajectories understood like temporal transition and not like identity experience (Grau, 2015). Since the introduction of the 2007 law, social movements and political agents (especially LGTBI NGO’s and PSOE-Spanish Socialist Worker's Party- political party, opposite to other more conservative parties, which 
main one is PP-Partido Popular-) have supported the need for LGBTI rights more broadly, and range of protective legislation has been introduced (for example, Galicia, law 2/2014; Catalonia, law 11/2014 and Estremadura, law 12/2015). Some Spanish regions have also developed their own laws to protect transgender rights and prevent transgender discrimination specifically (for example, Navarre, law 12/2009; Basque Country, law 14/2012; Andalucia, law 2/2014; Canary Islands, law 8/2014; and recently aproved in Madrid; March 2016).

The 2014 Andalucia law has been particularly significant for trans people in Spain. While other laws were focused on the discrimination of trans people, the 2014 Andalucia law was the first to introduce the right for gender self-determination, and also to depathologize trans identities by removing the requirement for psychological treatment or medical procedures in the gender recognition process. After this law was approved in Andalucia, other regions in Spain developed similar laws (mentioned above). The main difference between the 2007 national Spanish law and the Andalucian 2014 law is that while the first attempted to solve a legal vacuum (avoiding the required judicial process to demonstrate the personal gender identity and, consequently, to change the name and sex on Spanish identification cards), the Andalucian law employed the notion of citizenship as a framework for both gender recognition and trans rights more broadly. While these legislative changes have led to some rights being acquired, the question of whether the needs of trans people are now being met has, however, yet to be explored. In this paper, we argue that although legislative developments have been positive, socially entrenched norms of binary gender and heterosexuality underpinning the legislation remain problematic, causing many trans people to continue to face discrimination and social exclusion. Here, we illustrate the ways in which a socially entrenched heteronormativity creates pressures to comply with gender norms and how this can impact negatively upon trans people's mental health and well-being, where 
'well-being' is understood to occur when physical, emotional, social and sexual needs are met (Lopez, 2008).

\section{Ecological systems theory}

It is well documented that trans people's experiences of being trans, accessing and using medical services, and establishing identities in everyday life are all influenced by sociocultural forces (Westbrook \& Schilt, 2014; Hines \& Sanger, 2010). Thus there is an interplay between the personal aspects of the individual and their specific environment (Monro, 2003). Bronfenbrenner's (1989) ecological systems theory, which postulates that development and wellbeing is an evolving function of person-environment interaction, offers a useful framework through which trans people's experiences can be explored. The socioecological framework distinguishes among 'proximal' and 'distal' influences, formulated in four systems that interact with each other: the micro-level of self and immediate relationships with family and peers; the meso-level, or connections between micro-level contexts; the exosystem of social contexts beyond an individual's direct contact; and the macrolevel of a community's shared culture and values (1989). According to this model, people, relationships, community, and societal structures interact and influence each other, creating dynamics responsible for a variety of behaviors. In this paper, we draw on the socialecological framework to characterize the multiple and interacting levels of influence upon trans people's experience and their mental health and wellbeing. The microsystem includes face-to-face environments like the family, school or work context, partner, friends and interactions within medical settings. The mesosystem consists of the interactions between these microsystems(e.g., relationship between family and school). The exosystems are indirect links to the person, such as the region of the country, neighborhood-community context or the institutional systems (e.g. health system). Finally, the macrosystem constitutes institutional patterns of the culture and includes explicit manifestations, in laws and social 
policies, and implicit manifestations of ideology, which include societal norms, such as heteronormative gender and sexuality. The interrelations among these are important insofar as people will spend time in several systems at the same moment.

\section{Distal influences: the cultural pressure of heteronormativity}

Questions concerning the relationship between gender, sexuality and citizenship has emerged as an increasingly important area of debate (Lombardo \& Bustelo, 2012; Platero, 2011). A central issue within current discussions is the role of heteronormativity: the cultural assumption that heterosexuality is the only valid social norm; that gender is binary (there are only two genders, male and female); and that there is a "natural" alignment between anatomical sex, gender identity and (hetero) sexual orientation (Butler 1990; Stryker, 2008). What is defined as "normal" sexuality and "appropriate" (heterosexual) gender expression is constructed and reinforced through culture (Butler, 1990; Schilt \& Westbrook, 2009; Westbrook \& Schilt, 2014). Thus, men and women are expected to have male or female bodies that match their gender identities and engage in sexual practices with the "opposite" sex. This exerts significant 'distal influence' on the social organization of sexuality and the construction of gender, where non-heterosexual sexualities and non-conforming expressions of gender are seen to be problematic and stigmatized (Rich, 2003; Butler, 1990; Hines \& Sanger, 2010). For example, gender non-conforming and LGBT individuals may encounter homophobia and transphobia (Worthen, 2016) and also a range of barriers when seeking work or promotion (Johnson \& Ghavami, 2011; Whittle et al., 2007; Schilt \& Wiswall, 2008). Heteronormative social expectations around sexuality and gender underpin this social inequality, where the rights of those who do not conform to the heteronormative narrative are also often undermined (Gil, 2008). 


\section{Proximal influences: heteronormative interpersonal pressures and trans well-being}

Trans people experience a number of cultural pressures regarding gender and sexual norms because they do not conform to the cultural and psychosocial expectations that gender identity is an immutable derivation of biology (Westbrook \& Schilt, 2014). These pressures exert most influence psychosocially, for example, through interpersonal relationships where pressures related to gender or sexual exclusion have a direct affect upon trans people's wellbeing. The social construction of gender and sexuality, operating through heteronormative social processes, generates an ideological master narrative of the naturalness of heteronormativity that permeates social life (Butler, 1990), where those around trans people may unwittingly or deliberately place pressure on them in a direct and personal way. For example, it is usual for trans people to encounter a variety of 'microaggressions' from people around them in their daily lives (Nadal, et al., 2012; Nordmarken, 2014). These can include a lack of respect for and/or acceptance of their gender identity (Schilt \& Westbrook, 2009), the use of denigrating language and/or deliberate use of incorrect gender pronouns; Nadal et al, 2012), an undermining of their sense of community belonging, such as being accused of not being 'trans enough' (Leary et al., 1995; Galupo, Henise \& Davis, 2014), a negation of their sexual needs (Davy \& Steinbock, 2012) or, conversely, being exoticized (Nadal, Davidoff, Davis \& Wong, 2014). Thus, regular experience of microsagressions and the pressure to engage with and/or conform to norms of gender and sexuality exposes trans inviduals to various levels of psychosocial stress that have a negative impact upon their psychological well-being (Mayock et al., 2009).

Various international studies have demonstrated a direct relationship between cultural pressures concerning gender and sexuality and direct psychosocial pressure at the interpersonal level (Dysart-Gale, 2010; Fernández-Rouco et al., 2016; Schilt \& Westbrook, 2009). For example, trans people have typically reported a distant relationship and a high fear 
of victimization from their parents (Floyd et al., 1999). Further, it has been well documented that many trans people suffer from rejection, bullying, and lack of friendships (Griffen, Wilson \& Wren, 2005; Lombardi, 2009), and also a lack satisfactory and healthy romantic relationships (Dank et al., 2014). Finally, school and work contexts are often prime sites for discrimination, with many trans people, leaving school to avoid violence or rejection by peers (Williams et al., 2003; Loutzenheiser, 2015), thus putting future opportunities to develop a career or gain work at risk (Forman, 2003; Dietert \& Dentice, 2009; Whittle et al., 2007).

Discrimination is also present in institutions that are meant to defend and protect trans people's well-being. For example, a high level of discrimination is perceived by trans individuals in medical services (Burgess et al., 2008; Grant et al., 2010). This entire situation may lead trans people to have feelings of shame and stigmatization (Jupp, 2013).

In summary, heteronormative cultural pressures are associated with rejection and discrimination, a lack of support and the presence of stigmatization, isolation, transphobia, and violent behaviours towards trans people (Budge et al., 2013; Meyer, 2003). Poor mental health and well-being, and also a higher risk of risky sexual behavior have been identified as occurring largely as a consequence (Budge et al., 2013; Ryan, et al., 2009). Due to Spain’s heteropatriarchal state, where gender inequality and sexism operate on both structural and cultural levels, trans women have been particularly stigmatized as by transitioning from male to female, and deviating from their expected gender role, prior social status is lost (Sirin, McCreary \& Mahalik, 2004). Further, as in other European countries, there are cultural challenges to the legitimacy of their new social status. Within this context, trans women report higher levels of isolation, stigmatization, social exclusion, loneliness, more incidents of sexual risk taking behaviors, and also difficulties accessing education, cultural resources and services and the labour market, compared to trans men and cisgender men and women (Hoffman, 2014; Sevelius, Reznick, Hart \& Schwarcz, 2009). Further, trans women have been 
found to be more likely to become involved in sex work (Clements-Nolle et al., 2001, Baral et al., 2013). As Bockting et al (2013) observe, the interaction of these factors are significant in decreasing overall health and well-being .

\section{Methodology}

To explore the above issues in the lives of trans people in Spain, a qualitative research approach was adopted where the research focused on first hand experiential accounts of Spanish trans people regarding their everyday lives and relationships. The research sample was generated through the use of the snowball technique (Atkinson \& Flint, 2001), which resulted in semi-structured interviews being carried out with 120 trans people from different regions of Spain (e.g., Madrid, Canarias, Cataluña, Castilla \& León). Of the participants, 60 were trans men and 60 were trans women and ages ranged from 18 to 63 for women and 18 to 52 for men. The interviews were designed to explore different aspects of participants biographies linked to human needs and wellbeing dimensions (López, 2008), and were organized by a range of topics, including gender identity (e.g. "What situations make you feel bad regarding your gender identity?’), family, social, community, romantic and sexual relationships (e.g. "How is the relationship with your family/friends/partner regarding satisfaction?"), school or employment (e.g. "What was the reason you stopped studying?"), psychosocial risks and mental health (e.g. "Have you ever been discriminated against by any professional?"). During the interviews, participants were also encouraged to reflect on the current political situation in Spain regarding trans equality (and also trans equality in the past, if applicable), their experiences and feelings associated with the current situation, and the support and barriers they encounter in everyday living. All the interviews lasted for approximately 90 minutes and were carried out in a private room in a location chosen by the participants (either in their own home or another venue, such as a university). As some 
participants did not want the interview to be recorded, notes were made by the interviewers throughout the interviews.

A high standard of ethical integrity was adhered to throughout the research. Participants were provided with a full outline of the aims and objectives of the study and informed consent from each participant was gained before the interviews were carried out. Participants were also assured of confidentiality, anonymity and informed of the right to withdraw from the study at any time. The data drawn from the interviews was analysed using an inductive thematic analysis approach (Braun \& Clarke, 2006; 2014), where similarities and differences of experience were systematically identified and clustered into relevant analytical themes. In the following sections, discussion of the data is ordered around two main issues: participants experiences of gender and sexuality and how these were connected to cultural, social and psychological pressures; and how these pressures interacted with participants experiences of their mental health and well-being.

\section{Results}

\section{Family settings.}

Existing empirical research on trans people's lives shows familial relationships as being particularly significant to the experience of being trans. For example, family relationships are often the most difficult to negotiate when coming out as trans and/or going through the transitioning process. Whilst the family can provide much needed support for some, others may face hostile reactions from family members and ultimately rejection (Hines, 2007; Sanger, 2010 ; Whitley et al., 2013). Participants within this study offered similar accounts, describing tensions with family members, or situations where they were rejected, as being caused by not "fitting in" with their families expectations in relation to gender norms. As one transwoman we interviewed recalled, "When I told them at home, my father kicked me out" (Transwoman, 46 years old). Many reported how this generated the 
need for secrecy, such as attempting to 'pass' as their desired gender only when away from the family and without them knowing, or hiding true feelings in order to avoiding conflict and potential rejection. For example, one participant stated:

I always knew I did not fit what they expected of me but it took me a long time to say so. Everything I heard at home about gender and about how boys and girls should be made me feel excluded and as I grew up it gradually got worse.

Transwoman, 44 years old

Many participants described their family environments as unsupportive and intolerant and had felt unable to live as their desired gender until much later in life. One transman, for example, described how his family had added to the difficulties he faced when younger and also when transitioning:

When I was 14 or 15, I, I didn't want to be called a lesbian, and I couldn't wear my hair the way I wanted, dress the way I wanted, or go by the name I wanted... I remained silent for too long [...] My family always knew I didn't feel like a girl, but even when I told them I was transitioning, they never accepted it and they continued using my birth name. It was so embarrassing.

Transman, 28 years old

Both accounts above illustrate how the attitudes of family members were affected by social expectations concerning the gender binary and heteronormative gender expression, and how this then led to the interviewees experiencing pressure to hide their identity and feelings and be silent. However, for some participants, the need to keep their trans identity a secret 
was not only tied to a fear of rejection but a fear of homophobic and transphobic responses they would likely receive from family members. This also included violence, as one transwoman explained:

My father abused my mother until he died and at home I always heard him talking about fagots, deviants ... how could I say that I was a woman? ... my father would have killed me.

Transwoman, 51 years old

Similar to the experiences of the trans people in Brill and Pepper's (2008) research, the accounts of all the participants highlighted how their families could cause significant stress as they sought to understand, claim and develop their gender identities. In many cases, while participants' families exhibited otherwise good relationships, these were often superficial. This was largely due to family members being in denial or refusing to accept participants' identities and lifestyles. As one participant remarked:

I have my mother and my sister, but I never actually ask for their support. We meet to eat or something like that, but if something happens to me, I cannot expect their help, maybe in the case of money, but not with other problems, I don't feel understood.

Transwoman, 26 years old

In these cases, family relationships were fragile where there were no feelings of acceptance or support. Participants often referred to not being entirely accepted by family members, and also reported how speaking with their families about the experience of being trans was taboo and unwanted. Thus, instead of emotional support being provided by family 
members, the issue of gender identity was instead kept silent and hidden, leaving the participants to cope with their experiences alone (Factor \& Rothblum, 2007). From the accounts given by the participants, this experience also led them to be misgendered on a regular basis, whereby they then become somewhat distant from their families:

I'd rather not talk about this with my family. I speak very little with them because they don't stop using the masculine pronoun to refer to me, and I feel so humiliated. They are my family and although I ask them to change it, they ask me to understand them... it's a lot of pressure.

Transwoman, 48 years old

Paricipants accounts of their families highlighted how home and familial relationships were often far from being places of safety and support. Growing up as a young trans person involved various forms of gender identity rejection which, according to López (2008), should be considered as a form of child abuse.

While heteronormativity operates in all countries, Spain is distinctive insofar as it is also Catholic and conservative in character whereby heteronormatity is tied to faith as well as culture. For trans women the rejection of male privilege afforded them at birth leads to them being punished for being 'weak men', and also for failing to meet the expectations of femininity (Serano, 2007). In addition, in this conservative context, children who do not conform to the gender norms are seen to shame the family, thus generating a pressure within families to deny the child's identity and ignore their needs. This suggests that while legislative changes have led to some improvements for trans people in terms of equality and citizenship, a number of cultural problems nonetheless remain. 


\section{Friendship and romantic relationships.}

As Maycock et al (2009) observe, friendship ties and a sense of belonging are crucial within LGBT communities to help manage 'minority stress' (Mayock et al., 2009). Some studies highlight that networks emerge as a key component to LGBTI identity in a different way for young and older people, where the young are offered a level of insulation from the discriminative attitudes of family members and the larger culture, and the older experience a lack of LGBT community and higher stigma through the compartmentalisation of their behaviour. For some this is associated with changes on traditional gender ideologies and religious-based moral values (Severson et al., 2013). In contrast, regardless of age many of the participants in our study did not have a close friend with whom to talk to and share their emotions and experiences. As Hines (2007) observes, many trans people develop social relationships with other trans people in order to create support networks. Transgender groups and associations are often successful in facilitating such networks and for some, may be the only place where their identity is fully accepted and recognized. As one participant remarked :

I do not go out with friends, I have no friends, I just go to association meetings. Those Saturdays are my time, because that's when we all go out and have a drink together, and when I feel free. At the moment I cannot be myself anywhere else.

Transman, 25 years old

It is well documented that some trans people may have difficulties obtaining social support and are left to themselves to deal with issues of segregation (Robles, 2000) and feelings of loneliness and isolation (Budge et al., 2013; Griffen, Wilson \& Wren, 2005). The accounts of these participants, however, revealed informal community resources such as associations and support groups to be important insofar as they provided understanding 
environments where social pressures were understood and they could 'be themselves'. Friendships forged within such settings thus played a crucial role as it was through these friendships that participants' social and emotional needs were met (Bockting et al., 2013). As Hines (2007, p. 483) observes, relationships developed within associations and support groups are also signigficant insofar as they "fill in the gaps in care left by professional organizations."

For many participants, romantic relationships were the most difficult relationships to negotiate. Heteronormative cultural assumptions and expectations led many to feel that their gender would be considered invalid or fake by others, and that they would ultimately be rejected by potential sexual partners. As the following transwoman noted:

It is very difficult to have a long and successful relationship, especially if you are heterosexual like me, because of course, he can love you very much but at the moment you introduce yourself to the family, especially the mother, he does not want to... and their friends, $\ldots$ and it makes you feel rejected and it doesn't really end well.

Transwoman, 38 years old

This account highlights how social norms of gender can be powerful - that although establishing sexual contacts may not in themselves be difficult, they can become so once the relationship moves beyond the private sphere where there is a risk of "relationship stigma" (Gamarel et al., 2014). All of the participants recounted regular experiences of romantic loneliness and low levels of relationship satisfaction (see also, Dank et al, 2014).

\section{School and work contexts}


Trans people are exposed to a broad range of stressors in social contexts such as school and work. Stigma and discrimination generates exclusion, making school experiences difficult and painful for young trans people, amd causing difficulties in gaining employment or succeeding at work in the case of trans adults (Griffen, Wilson \& Wren, 2005). Due to the pressures trans people face as a direct result of discrimination and stigma, many avoid applying for jobs, stop attending work or drop out of school (Bockting et al., 2013). In the following accounts, a trans man and transwoman both recount reasons for quitting school:

I could not study, I would have liked to, but at 14 years old I had already dropped out and begun my transition. It was the only way, I had no choice. I started selling in the street as a sex worker, but I would have liked to have been a teacher.

Transwoman, 55 years old

I studied until high school, but then I left. I could not to be stand to be called by my legal name, or be called a lesbian. I looked for what work there was, and I continue to do this, working when I can, in what becomes available

Transman, 28 years old

As illustrated here, some trans people leave school because of difficulties being accepted during the transition process. This can then lead to poor job prospects with some, particularly trans women, moving into sex work out of necessity in order to survive.

For other participants, gaining employment and succeeding at work had been particularly problematic. One participant, for example, recounted how accessing work, even 
in lower paid occupations, was difficult and that she had not been successful in gaining employement due to her gender non-conforming appearance:

I have never worked in a store, they always tell me the same thing, I don't fit the profile, but of course, it's a lie. I know why I don't fit the profile, I have no physical traits of a biological woman...

Transwoman, 31 years old

For another participant, transitioning had been problematic during his training for work as a mechanic due to his gender identity being invalidated by colleagues. This experience then led him to hide his trans status when applying for work, due to a fear that this invalidation of his identity would continue:

I always wanted to work as a mechanic, but when I looked for work, they told me that it was not a job for women. I enrolled in a course and they don't consider me as valid because I was a woman for my colleagues, it was very difficult for me to finish it. Now I've made the transition, but I never talk about it, and I work in a car shop.

Transman, 29 years old

As highlighted in these extracts, being trans often means experiencing rejection by others and being excluded from fully participating in local communities and workplaces. Both participants discussed here recount their rights being violated and their identities rejected. It is situations such as these that lead to feelings of loneliness, isolation and rejection, and also weaken everyday social networks necessary to gain access to certain relationships and social spaces, such as school and work settings (Martínez, 1999). As described by one participant:

I had a hard time at work, and generally in my life, so I stopped work to transition. I spent a long time without work and without leaving home, where I became depressed and 
anxious. I was, waiting for transition to change my life so that I could leave the house and look for work. I have spent almost 3 years alone. I still feel lonely because nobody knows my situation at work, but at least nobody discriminates me.

Transman, 25 years old

As illustrated here, school and work settings are often discriminatory and unsatisfactory for trans people, and significant sources of unhappiness and stress (Williams et al., 2003).

\section{Well-being, mental health and medical services}

All of the participants recounted how social and psychological pressures concerning their gender identities and gender expression and, in many cases consequent victimization, generated a high degree of psychological distress which had significant affect upon their mental health and general well-being regardless their age. One transman, for example, described how he regularly experienced social exclusion, stating that:

Being excluded affects everything, and makes you believe you are outside of everything, you feel bad, you feel helpless, and I do not want to complain all the time, but it's very difficult, it gets very difficult.

Transman, 26 years old

Similarly, some of those interviewed referred to the discomfort they felt due to social and interpersonal pressures. These participants explained how social isolation and the lack of people to talk to, due to difficulties in gaining acceptance, had led to loneliness and feelings of helplessness: 
I'm single, I have no close friends, and I can't talk with my family, so I went to a psychologist, because I was feeling very badly and didn't know how to change it. That's why I am here, it's an opportunity to talk and feel better.

Transman, 34 years old

I went to live in another city to start a new life and not have to tell anyone about my transition, I hoped to be happy, but it has been very hard, because I felt very lonely and if something happened to me, nobody really knew who I am.

Transwoman, 36 years old

A significant issue that arose within the accounts of the transwomen participants was how psychological distress, as well as frequent experiences of violence and other forms of victimization, often contributed to engaging in sexually risky behaviour. One participant, for example, recounted how the desire to be accepted by men as a heterosexual woman had resulted in her contracting HIV:

I knew I had HIV a few years ago, but I think I'd been infected for a long time. When I started to present as who I am, as a woman, I was so depressed and alone, and once I saw I could be with men as a woman, I just hoped that they would accept me and I didn't think about condoms or anything else.

Transwoman, 44 years old

Psychosocial pressures can, then, lead to risky sexual behaviour and sexual health care problems, particularly for trans women. For example, as shown in the above extract, sexual health risks and safe sex practices, such as using condoms, may not be considered and 
adopted when the main goal of their sexual relationships is to be loved by another person (Bockting, Robinson \& Rosser, 1998). Psychosocial and cultural pressures are, then, inextricably linked, affecting mental health and well-being, and sometimes causing health issues such as STDs. As the above extract also illustrates, this is also linked particularly strongly to pressures to conform to heteronormative binary gender norms in order to gain gender affirmation. There is a need, therefore, for social policy makers to consider the importance of social inclusion measures to support the current law, and to facilitate social tolerance and critical awareness around trans and gender issues (Gil, 2008).

The participants within this study all recounted experiences that suggest the need for the revision of current mental health and care services. The available resources intended to provide social, medical and legal support to trans people were described as functioning from a heteronormative ideology, and often inefficient, even negligent. One participant, for example, described how he had been treated "very badly" by one psychologist:

It depends on the psychologist, but I went to one who treated me very badly, they told my family I had to be medicated and that we had to do therapy to resolve my identity conflict. I was young and went to several psychologists until finally I found a professional who made the process easier for me, but I had a hard time until then. During this time I lost hope of starting my transition.

Transman, 41 years old

Despite the recent legal regulation, the participants described how medical procedures are invariably linked to heteronormative binary norms of gender and sexuality. For the participants a high degree of psychological distress was generated in their engagement with medical processes and practitioners, as one transman explained: 
I had been waiting for years for the psychological report so that I could begin the hormone therapy. In his opinion I had not lived long enough as a man ... I had lived all my life as a man! And now even longer with the hormone treatment and yet am unable to have surgery. I can't do it anymore. Everyday I go to work with this body, I go and I feel insecure and in a bad mood.

Transman, 27 years old

As in other studies (Norton \& Herek, 2013), our research revealed that legal and formal rights did not guarantee social acceptance or prevent transphobia. Most of the participants described having been forced to manage bodies that belied their gender identities, often for years, due to rigid medical protocols. As well as exacerbating symptoms of gender dysphoria (Levine, 2009), this meant living with constant fear of hate crime (Hein et al., 2013) and dealing with ongoing discrimination in their daily lives, all of which had a severe impact on their mental health and wellbeing. As Budge et al. (2013) observe, transgender transitions are sometimes understood by health professionals as being the same experience for all trans persons, where stages and experiences are idealized. However, as discussed here, far from being ideal, these procedures are related to higher levels of loneliness, anxiety and hopelessness for many trans people.

In summary, the accounts of participants reveal the necessity to work towards generating an inclusive social model of gender, requiring policy makers to take on the challenge of reconceptualising gender categorisation (Monro, 2003) and thus work towards transforming gender discourses more broadly. It is noteworthy to state that developments in legislation, cultural and psychosocial pressures, and trans people's health well-being are influenced by each other. What can be concluded from the accounts discussed here, is that 
although the legal framework has improved in Spain during the last decade, the influence of heternormativity and its effects on individuals' social spheres has a greater influence on individuals' well-being than legislation. While law is a necessary instrument to ensure citizenship, changes in social norms and understandings are also required if the needs of trans people are to be fully met (Pichardo, Molinuevo \& Riley, 2009).

\section{Conclusions}

Heteronormativity has a direct influence on the quality of trans people's lives and their mental health and well-being. It exerts cultural pressure on trans people to meet and/or adjust to dominant norms of gender and sexuality. As trans people are often not able to meet these norms before obtaining gender confirming treatment and legal gender change (or indeed have no wish to meet such norms), they are considered to be "deviant outsiders" and as a consequence become stigmatized (Moolchaem, 2015). This paper drew on interviews with trans people to highlight the cultural and psychosocial pressures that trans people encounter in Spain due to deeply entrenched heteronormative social norms and expectations. The cultural pressures of heteronormativity upon trans people has been seen to occur most poignantly through psychosocial pressures experienced in relation to family, friends and romantic relationships, and also education, work and mental health settings regardless of age and existing laws. The analysis presented here illustrates the significance of proximal and distal interactions in the lives of trans people, and how heteronormativity crosses the socioecological systems, as defined by Bronfenbrenner (1989). The discussion of participants' accounts also illustrate how exclusion can seriously affect the self-identities of trans people, leading to feelings of loneliness, helplessness and, for some trans women, risky sexual behavior, all of which impact severely upon mental health and well-being. The accounts discussed further highlight the insufficient, inefficient (or even negligent) support that many receive from mental health resources. Transgender transitions are sometimes understood by 
health professionals as a defined process with defined steps, which excludes those experiences that do not fully fit, increasing levels of loneliness, anxiety and hopelessness for many trans people. Contrary to previous studies in Spain, this study illustrates the multiple pressures that trans people face in different spheres of their lives and how these connect to the dominant social model of gender and also the Spanish legal context. Further, our heterogeneous sample enabled us to access polyphonic and multi-vocal stories where the personal narratives revealed the importance of talking about experience from particular identities (Peralta \& Mérida, 2015).To improve the situation of trans people in Spain there is a need for further legislative change. While recent changes have certainly made a move towards improving the mental health and well-being of trans people, for example, enabling a change of name and sex on identification cards or revising the requirements for gender correction treatments, there are numerous strict requirements which exert pressure to demonstrate a fit with heteronormative binary gender ideals. Thus, while legal changes are of paramount importance for the recognition of rights and citizenship, this does not guarantee changes in social attitudes towards gender norms. It is, then, crucial for policy makers to challenge gender categorization and work towards transforming public discourses on gender issues.

Although the data presented here provides new, current and interesting information about the situation of trans people in Spain, it does have some limitations. The paper did not, for example, adopt an intersectional approach and address the issues discussed across ethnic, social, racial, national, economic and many other boundaries. An intersectional approach would be useful in extending the findings of this research. In addition, the snowball sampling method used placed limitations on the research sample. For example, the sample could not be conrolled for diversity or representativeness. Nevertheless, the method does facilitate access to populations that are difficult to reach when using other sampling methods. Further, the research discussed here did not adopt a longitudinal approach and analyze the participants 
accounts across time. As such, the ongoing impact of legislative change upon the participants lives and experiences over time has not been explored. The research does, however, provide more knowledge about the effect of heteronormativity and psychosocial pressure on the mental health and well-being of Spanish trans people, which to date remains largely under researched. Finally, the research has further relevance insofar as it explores different human systems, both distal and proximal, and reflects how legal changes are not in themselves enough to bring about social change.

\section{References}

Atkinson, R., \& Flint, J. (2001). Accessing hidden and hard-to-reach populations: Snowball research strategies. Social research update, 33(1), 1-4.

Bockting, W.O., Miner, M.H., Swinburne, R.E., Hamilton, A., \& Coleman, E. (2013). Stigma, mental health, and resilience in an online sample of the U.S. transgender population. American Journal of Public Health, 103(5), 943-951.

Bockting, W.O., Robinson, B.E., \& Rosser, B.R.(1998). Transgender HIV prevention: A qualitative needs assessment. AIDS Care, 10(4), 505-525.

Braun, V., \& Clarke, V. (2006). Using thematic analysisin psychology. Qualitative Research in Psychology, 3, 77-101.

Baral, S. D., Poteat, T., Strömdahl, S., Wirtz, A. L., Guadamuz, T. E., \& Beyrer, C. (2013). Worldwide burden of HIV in transgender women: a systematic review and metaanalysis. The Lancet infectious diseases, 13(3), 214-222.

Brill, S., \& Pepper, R. (2008). The transgendered child: a Handbook for Families and Professionals. San Francisco: Cleis Press Inc.

Bronfenbrenner, U. (1989). Ecological systems theory. In R. Vasta (Ed.), Six theories of development (pp. 187-249). Greenwich, CT: JAI Press. 
Budge, S.L., Katz-Wise, S.L., Tebbe, E.N., Howard, K.A.S., Schneider, C.L., \& Rodriguez, A. (2013). Transgender emotional and coping processes: Facilitative and avoidant coping throughout gender transitioning. The Counseling Psychologist, 41(4), 601-647.

Burguess, D., Lee, R., Tran, A., \& Van Ryn, M. (2008). Effects of Perceived Discrimination on Mental Health and Mental Health Services Utilization Among Gay, Lesbian, Bisexual and Transgender Persons. Journal of LGBT Health Research, 3(4), 1-14.

Bustelo, M. (2009). Spain: Intersectionality faces the strong gender norm. International Feminst. Journal of Politics, 11, 530-546.

Butler, J. (2002) Cuerpos que Importan.Sobre los límites materiales y discursivos del sexo. Buenos Aires: Paidós.

Butler, J. (1990). Gender trouble: Feminism and the subversion of identity. London: Routledge.

Carpenter, M. (2009.) The capabilities approach and critical social policy: Lessons from the majority world? Critical Social Policy, 100, 351-373.

Clarke, V., \& Braun, V. (2014). Thematic analysis. In T. Teo (Ed.), Encyclopedia of Critical Psychology (pp. 1947-1952). New York: Springer.

Clements-Nolle, K., Marx, R., Guzman, R., \& Katz, M. (2001). HIV prevalence, risk behaviors, health care use, and mental health status of transgender persons: implications for public health intervention. American Journal of Public Health, 91(6), 915-921.

Cooper, D. (1995). Power in Struggle: Feminism, Sexuality and the State. Buckingham: Open University Press.

Daley, A., Salomon, S., Newman, P., \& Mishna, F. (2007). Traversing the margins: Intersectionalities in the bullying of lesbian, gay, bisexual and transgender youth. Journal of Gay and Lesbian Social Services 19(3/4), 9-29. 
Dank, M., Lachman, P., Zweig, J.M., \& Yahner, J. (2014). Dating Violence Experiences of Lesbian, Gay, Bisexual, and Transgender Youth. Journal of Youth and Adolescence, $43,846-57$.

Davy, Z., \& Steinbock, E. (2012). 'Sexing Up’ Bodily Aesthetics: Notes towards Theorizing Trans Sexuality. In Sexualities: Past reflections, future directions (pp. 266-285). Palgrave Macmillan UK.

Dean, H. (2009). Critiquing capabilities: The distractions of a beguiling concept.Critical Social Policy, 29(2), 261-278.

Dysart-Gale, D. (2010). Social justice and social determinants of health: LGBTIQ youth in Canada. The Journal of Child and Adolescent Psychiatric Nursing, 23(1), 23-28.9

Dietert, M., \& Dentice, D. (2009). Gender identity issues and workplace discrimination: The transgender experience. Journal of workplace rights: JWR, 14(1), 121.

Factor, R.J., \& Rothblum, E.D. (2007). A study of transgender adults and their nontransgender siblings on demographic characteristics, social support, and experiences of violence. Journal of LGBT Health Research, 3, 11-30.

Fernández-Rouco, N., Fernández-Fuertes, A., Carcedo, R., Lázaro-Visa, S., \& Gómez-Pérez, E. (2016). Sexual Violence History and welfare in transgender people. Journal of Interpersonal Violence, 1-23. DOI: 10.1177/0886260516657911.

Floyd, F.J., Stein, T.S., Harter, K.M., Allison, A., \& Nye, C.L. (1999). Gay, lesbian, and bisexual youths: Separation-individuation, parental attitudes, identity consolidation, and well-being. Journal of Youth and Adolescence, 28(6), 719-739.

Forman, T.A. (2003). The Social psychological costs of racial segmentation in the workplace: A study of African Americans' wellbeing. Journal of Health and Social Behavior, 44, $332-352$. 
Galupo, M. P., Henise, S. B., \& Davis, K. S. (2014). Transgender microaggressions in the context of friendship: Patterns of experience across friends' sexual orientation and gender identity. Psychology of Sexual Orientation and Gender Diversity, 1(4), 461470.

Gamarel, K. E., Reisner, S. L., Laurenceau, J. P., Nemoto, T., \& Operario, D. (2014). Gender minority stress, mental health, and relationship quality: A dyadic investigation of transgender women and their cisgender male partners. Journal of Family Psychology, 28(4), 437-447.

Gil, F. (2008). Racismo, homofobia y sexismo. Reflexiones teóricas y políticas sobre interseccionalidad. In: Wade. P., Urrea F and Viveros M (eds). Raza, etnicidad y sexualidades: ciudadanía y multiculturalismo en América Latina (pp.485-512). Bogotá: Universidad Nacional de Colombia, Centro Latinoamericano de Sexualidad y Derechos Humanos.

Grant, J. M., Mottet, L. A., Tanis, J., Herman, J. L., Harrison, J., \& Keisling, M. (2010). National transgender discrimination survey report on health and health care. Washington, DC: National Center for Transgender Equality and the National Gay and Lesbian Task Force.

Grau, J. M. (2015). Transexualidad y transgenerismo. Una aproximación teórica y etnográfica a dos paradigmas enfrentados. Revista de Dialectología y Tradiciones Populares, 70(2), 485-501.

Griffen, I., Wilson, I., \& Wren, B. (2005). The interaction between young people with atypical gender identity organization and their peers. Journal of Health Psychology, $10,307-315$.

Hein, L. C., \& Scharer, K. M. (2013). Who cares if it is a hate crime? Lesbian, gay, bisexual, and transgender hate crimes - mental health implications and 
interventions. Perspectives in psychiatric care, 49(2), 84-93.

Hines, S. (2007). Transgendering Care: Practices of Care within Transgender Communities. Critical Social Policy, 27(4), 462-486.

Hines, S., \& Sanger, T. (Eds.) (2010) Transgender identities: Towards a social analysis of gender diversity. Routledge.

Hoffman, B. (2014). An overview of depression among transgender women. Review article. Depression research and treatment,1-9. DOI: 10.1155/2014/394283.

Johnson, K., \& Ghavami, N. (2011). At the crossroads of conspicuous and concealable: What race categories communicate about sexual orientation.PLoS ONE, 6, e18025.

Jupp, E. (2013). I feel more at home here than in my own community: approaching the emotional geographies of neighbourhood policy. Critical Social Policy, 33(3), 532553.

Kessler, S., \& McKenna, W. (1978). Gender: An Ethnomethodological Approach. New York: John Wiley \& Sons.

Levine, S. B. (2009). Real-life test experience: Recommendations for revisions to the standards of care of the world professional association for transgender health. International Journal of Transgenderism, 11(3), 186-193.

Leary, M.R., Tambor, E.S., Terdal, S.K., \& Downs, D.L. (1995). Self-esteem as an interpersonal monitor: The sociometer hypothesis. Journal of Personality and Social Psychology, 68, 518-530.

Lombardo, E., \& Bustelo, M. (2012). Political Approaches to Inequalities in Southern Europe: A Comparative Analysis of Italy, Portugal, and Spain. Social Politics: International Studies in Gender, State and Society, 19(4), 572-595.

Lombardo, E., \& Verloo, M. (2010). La interseccionalidad del género con otras desigualdades en la política de la Unión Europea. Revista Española de Ciencia Política, 23, 11-30. 
Lombardi, E. (2009). Varieties of transgender/transsexual lives and their relationship with transphobia. Journal of homosexuality, 56(8), 977-992.

López, F. (2008). Necesidades en la infancia y en la adolescencia. Respuesta familiar, escolar y social. Madrid: Pirámide.

Loutzenheiser, L. W. (2015). 'Who are you calling a problem?': Addressing transphobia and homophobia through school policy. Critical Studies in Education, 56(1), 99-115.

Mayock, P., Bryan, A., Carr, N., \& Kitching, C. (2009). Supporting LGBT Lives: A Study of the Mental Health and WellBeing of Lesbian, Gay, Bisexual and Transgender People. Dublin: Gay and Lesbian Equality Network.

Meyer, I.H. (2003). Prejudice, social stress, and mental health in lesbian, gay, and bisexual populations: Conceptual issues and research evidence. Psychological Bulletin, 129(5), 674-697.

Monro, S. (2003). Transgender Politics in the UK. Critical Social Policy, 23(4), 433-452.

Moolchaem, P., Liamputtong, P., O’Halloran, P., \& Muhamad, R. (2015). The lived experiences of transgender persons: A meta-synthesis. Journal of Gay \& Lesbian Social Services, 27(2), 143-171.

Nadal, K. L., Skolnik, A., \& Wong, Y. (2012). Interpersonal and systemic microaggressions toward transgender people: Implications for counseling. Journal of LGBT Issues in Counseling, 6(1), 55-82.

Nadal, K. L., Davidoff, K. C., Davis, L. S., \& Wong, Y. (2014). Emotional, behavioral, and cognitive reactions to microaggressions: Transgender perspectives. Psychology of Sexual Orientation and Gender Diversity, 1(1), 72-81.

Nordmarken, S. (2014). Microaggressions. Transgender Studies Quarterly, 1(1-2), 129-134.

Norton, A. T., \& Herek, G. M. (2013). Heterosexuals' attitudes toward transgender people. Sex Roles, 68(11-12), 738-753. 
Pichardo, J.I., Molinuevo, B., \& Riley, R. (2009). Achieving real equality: A work in progress for LGBT youth in Spain. Journal of LGBT Youth, 6(2-3), 272-287.

Peralta, J.L., \& Mérida, R. (2015). Memorias, identidades y experiencias trans. (In)visibilidades entre Argentina y España. Buenos Aires: Biblos.

Platero, R. (Lucas) (2012). Intersecciones: cuerpos y sexualidades en la encrucijada. Barcelona: Bellaterra.

Platero, R. (Lucas) (2012). ¿Son las políticas de igualdad de género permeables a los debates sobre la interseccionalidad? Una reflexión a partir del caso español.Revista del CLAD Reforma y Democracia, 5, 135-172.

Platero, R. (Lucas) (2011). The narratives of transgender rights mobilization in Spain. Sexualities, 14(5), 597-614.

Rich, A. (2003). Compulsory Heterosexuality and Lesbian Existence. Journal of Women's history, $15,14-48$.

Robles, F. (2000). El desaliento inesperado de la modernidad. Molestias, irritaciones y frutos amargos de la sociedad del riesgo. Chile: Sociedad Hoy.

Ryan, C., Huebner, D., Diaz, R.M., \& Sanchez, J. (2009). Family rejection as a predictor of negative health outcomes in white and Latino lesbian, gay and bisexual young adults. Pediatrics, 123(1), 346-352.

Sanger, T. (2010). Trans people's partnerships: towards an ethics of intimacy. Palgrave Macmillan.

Schilt, K., \& Westbrook, L. (2009), Doing Gender, Doing Heteronormativity: Gender Normals, Transgender People, and the Social Maintenance of Heterosexuality. Gender \& Society, 23(4), 440-464. 
Schilt, K., \& Wiswall, M. (2008). Before and after: Gender transitions, human capital, and workplace experiences. The BE Journal of Economic Analysis \& Policy, 8(1), 19351682.

Serano, J. (2007). Whipping girl: A transsexual woman on sexism and the scapegoating of femininity. Seal Press.

Sevelius, J. M., Reznick, O. G., Hart, S. L., \& Schwarcz, S. (2009). Informing interventions: the importance of contextual factors in the prediction of sexual risk behaviors among transgender women. AIDS Education \& Prevention, 21(2), 113-127.

Severson, N., Muñoz-Laboy, M., Garcia, J., Perry, A., Wilson, P., \& Parker, R. (2013). Generational Changes in the Meanings of Sex, Sexual Identity and Stigma among Latino Young and Adult Men. Culture, health \& sexuality, 15(7), 804.

Sirin, S. R., McCreary, D. R., \& Mahalik, J. R. (2004). Differential reactions to men and women's gender role transgressions: Perceptions of social status, sexual orientation, and value dissimilarity. The Journal of Men's Studies, 12, 119-132.

Stryker, S. (2008). Transgender history, homonormativity, and disciplinarity.Radical HistoryReview, 100, 144-157.

Susinos, T., \& Rodriguez-Hoyos, C. (2011). La educación inclusiva hoy. Reconocer al otro y crear comunidad a través del diálogo y la participación. Revista Interuniversitaria de Formación del Profesorado, 70(25), 15-30.

Tezanos, J. F. (2001). Tendencias en desigualdad y exclusión social. Madrid: Sistema.

Tolman, L. \& Diamond, M. (2014). APA handbook on sexuality and psychology. Washington: APA Press.

Turner, B. S. (2001). The erosion of citizenship. British Journal of Sociology, 2(52), 189-209.

Westbrook, L., \& Schilt, K. (2014). Doing gender, determining gender: Transgender people, gender panics, and the maintenance of the sex/gender/sexuality system. Gender \& 
Society, 28(1), 32-57.

Williams, T., Connolly, J., Pepler, D., \& Craig, W. (2003). Questioning and sexual minority adolescents: High school experiences of bullying, sexual harassment and physical abuse. Canadian Journal of Community Mental Health, 22(2), 47-58.

Whitley, C. T. (2013). Trans-kin undoing and redoing gender: Negotiating relational identity among friends and family of transgender persons. Sociological Perspectives 56(4), $597-621$.

Whittle, S., Turner, L., Al-Alami, M., Rundall, E., \& Thom, B. (2007). Engendered penalties: Transgender and transsexual people's experiences of inequality and discrimination. Wetherby: Communities and Local Government Publications.

Worthen, M. G. (2016). Hetero-cis-normativity and the gendering of transphobia. International Journal of Transgenderism, 17(1), 31-57. 